\title{
A NEW QUANTITATIVE APPROACH TO MEASURE PERCEIVED WORK-RELATED STRESS IN ITALIAN EMPLOYEES
}

\author{
GABRIELE CEVENINI ${ }^{1}$, ILARIA FRATINI ${ }^{2}$, and ROBERTO GAMBASSI ${ }^{3}$ \\ ${ }^{1}$ University of Siena, Siena, Italy \\ Department of Medical Biotechnologies \\ ${ }^{2}$ Human Resources Consultancy and Applied Social Research, Florence, Italy \\ ${ }^{3}$ University of Siena, and Microcosmos, Siena, Italy \\ Department of Quantitative Methods
}

\begin{abstract}
Objective: We propose a method for a reliable quantitative measure of subjectively perceived occupational stress applicable in any company to enhance occupational safety and psychosocial health, to enable precise prevention policies and intervention and to improve work quality and efficiency. Materials and Methods: A suitable questionnaire was telephonically administered to a stratified sample of the whole Italian population of employees. Combined multivariate statistical methods, including principal component, cluster and discriminant analyses, were used to identify risk factors and to design a causal model for understanding work-related stress. Results: The model explained the causal links of stress through employee perception of imbalance between job demands and resources for responding appropriately, by supplying a reliable U-shaped nonlinear stress index, expressed in terms of values of human systolic arterial pressure. Low, intermediate and high values indicated demotivation (or inefficiency), well-being and distress, respectively. Costs for stress-dependent productivity shortcomings were estimated to about $3.7 \%$ of national income from employment. Conclusions: The method identified useful structured information able to supply a simple and precise interpretation of employees' well-being and stress risk. Results could be compared with estimated national benchmarks to enable targeted intervention strategies to protect the health and safety of workers, and to reduce unproductive costs for firms.
\end{abstract}

Key words:

Multivariate statistics, Non productivity costs, Occupational safety, Prevention, Risk assessment, Work-related stress

\section{INTRODUCTION}

Stress is a condition accompanied by psychophysical effects generated by feeling of being unable to cope with demands or not coming up to expectations. The international scientific community has long held the view that workrelated stress profoundly affects worker health and safety, as well as company efficiency and productivity, with major consequences for the overall social environment [1-6]. Policy makers have recently realized that stress must be addressed responsibly because of its proven relationship with physical and mental illness [7-13].

The industrialized world has shown a growing interest in the development and implementation of prevention programs in the workplace. According to the modern model

Received: December 30, 2011. Accepted: July 13, 2012.

Address reprint request to G. Cevenini, Department of Medical Biotechnologies, University of Siena, Viale Bracci 16, 53100 Siena, Italy (e-mail: cevenini@unisi.it). 
of occupational health, it is essential to protect against, recognize, monitor and eliminate potential occupational risks. This includes psychosocial risks, for which in-depth interpretation and shared understanding of specific characteristics and their influences on human behavior are important to ensure adequate and effective risk prevention [14].

The recent strong focus on work-related stress at international level demonstrates the importance of this issue. In particular, the main European authorities responsible for ensuring good occupational conditions promote studies and applied experimental protocols for improved assessment of work-related stress, while urging governments to ratify agreements and enact laws to regulate occupational stress-reducing measures [15,16]. European employers perceive the problem as important: as many as $79 \%$ of European managers are worried about stress at work, though less than a third of companies have procedures to deal with it [17]. A recent report in the 27 European Member States has shown that stress is the second major cause of health problems in the workplace, affecting as many as $22 \%$ of workers and being responsible for 50-60\% of lost working days [18]. This is a huge cost in terms of human suffering and impairment of economic performance. Psychophysical health of employees in the workplace is crucial to the success of any organization [19]. Presenteeism, or the act of attending work while sick, influences non-productivity costs over twice as much as absenteeism [20].

The relationship between stress and heart disease was investigated by a recent systematic review which examined the results of many validated researches to demonstrate that work stress was related to biological mechanisms involved in the onset of heart disease [13].

An appropriate approach to work-related stress must investigate psychosocial aspects causing job strain through study of subjective perception of stressful occupational experiences [11]. Besides providing employers with useful information on the well-being of their employees, these studies should be able to suggest appropriate measures to improve labor quality and productivity, leading to higher and more sustainable business profit, to the benefit of all involved [17].

Over the last 30-40 years, many physiological, psychological and socioeconomic models have been proposed to describe and interpret the stress perceived by workers [1-7,21-23]. Some of them have gained popularity and have often been applied successfully to experimental data [24]. The validation of their effectiveness has sometimes led to conflicting results for many reasons, mainly related to the presence of different application contexts, i.e. assessment methods, populations or socioeconomic situations different from those on which the models were originally based $[10,24,25]$. The customization to the specific empirical conditions and updating to account for the effects of time-dependent phenomena are fundamental keys for the success of any estimation model [26].

The main goal of this study is to give an accurate quantification of the perceived occupational stress through a new quantitative approach of questionnaire data collection and analysis which leads to substantial advantages relative to conventional methods. In particular, we propose a statistical multivariate procedure for optimizing the design of an interpretative model of risk factors and causal relationships related to worker-perceived stress. Our model incorporates the most advanced and validated theories in this field but, contrary to standard techniques, creates scores which maximize the separation between actual empirical patterns, thus avoiding biases due to different levels of correlation between items. Moreover, our approach can easily discriminate the opposing expressions of occupational stress, i.e. due to lack of motivation or excessive workload, which is difficult to achieve using conventional techniques based on linear monotonic scales. We will use a stratified sample of the whole Italian employees population to provide a precise characterization of the studied population, also allowing to identify useful benchmarks 
related to interesting homogeneous sets of workers, such as for example, males and females, subjects that belong to specific geographical areas or to economic categories, and so on. The aim is to obtain a one-dimensional reliable estimation of occupational stress which could guide specialized psychologists and politicians to face adequately its socioeconomic consequences, through targeted intervention strategies to protect workers' health and safety and to control stress-related costs in companies [11,20,27].

\section{METHODS}

\section{Sample and population}

The study population consisted of nearly 19 million Italian employees. A sample of 2419 workers was identified by stratified sampling with proportional allocation to minimize sample size and error. Three stratification factors were considered: gender, economic activity (11 sectors) and geographical area (5 macro-regions). Table 1 gives the bi-dimensional percentage distributions of workers for sector of economic activity and geographical area. The average percentages of workers for gender were $57.3 \%$ and $42.7 \%$ for males and females, respectively. The data was obtained from the database of the Italian National Institute of Statistics (ISTAT). Of course, the percentages may be related to either the population or the sample, the latter being chosen in a proportional manner.

Minimum sample size provided at least one worker in each of the 110 combined strata. The $95 \%$ confidence interval of sample estimates and related sampling error were evaluated by the bootstrap technique "percentile corrected and accelerated" applied separately to each stratum. Bootstrapping is a highly computer-intensive statistical procedure used to produce good approximate confidence intervals when the statistical distribution of data is unknown or so complex that conventional techniques are not valid [28].

Seventy five per cent $(75 \%)$ of the whole main sample (1815 cases) were used as the training set while the remaining $25 \%$ (604 cases) were reserved for validating model

Table 1. Distributions of workers by economic field of activity and geographical area

\begin{tabular}{lcccccc}
\hline \multirow{2}{*}{ Economic field of activity } & \multicolumn{7}{c}{ Workers (\%) } \\
\cline { 2 - 7 } & $\begin{array}{c}\text { North } \\
\text { West }\end{array}$ & $\begin{array}{c}\text { North } \\
\text { East }\end{array}$ & centre & South & islands & total \\
\hline Agriculture, fishing, mining, electricity, gas and water & 0.4 & 0.4 & 0.3 & 0.4 & 0.2 & 1.6 \\
Manufacturing & 11.2 & 8.6 & 4.9 & 3.7 & 0.9 & 29.3 \\
Construction industry & 1.7 & 1.4 & 1.2 & 1.3 & 0.6 & 6.2 \\
Wholesale and retail trade; repair of cars, motorbikes & 3.7 & 2.6 & 2.2 & 1.5 & 0.8 & 10.7 \\
$\quad$ and personal property & & & & & & \\
Hotels \& restaurants & 0.9 & 0.9 & 0.8 & 0.4 & 0.2 & 3.3 \\
Transport, storage and communication & 2.2 & 1.4 & 1.7 & 1.2 & 0.5 & 7.1 \\
Financial intermediation and banking & 1.3 & 0.8 & 0.8 & 0.4 & 0.2 & 3.5 \\
Real estate, renting, information technology, research, & 3.5 & 1.9 & 2.0 & 1.1 & 0.4 & 8.9 \\
$\quad$ freelancer and contractor & & & & & & \\
Public administration and defense & 1.4 & 1.1 & 1.8 & 1.6 & 0.9 & 6.8 \\
Education & 2.3 & 1.8 & 1.9 & 2.8 & 1.4 & 10.3 \\
Health and other social services & 3.6 & 2.6 & 2.7 & 2.2 & 1.1 & 12.2 \\
Total activities & 32.2 & 23.5 & 20.3 & 16.6 & 7.4 & 100 \\
\hline
\end{tabular}


performance. Training and testing results were compared by the non-parametric Mann-Whitney test (significance level 95\%; $p<0.05$ ) to assess their statistical equality.

\section{Data collection and reduction}

Information for detecting work-related stress was acquired following mostly the model proposed by the European Agency for Safety and Health at Work [15] and compiled from previous studies $[2,29]$. Here, the most authoritative psychological approach has led to identifying the nature and detail of stress at work and its outcomes by considering both interpersonal labor aspects and the interaction with life outside the work [21,22]. Therefore, although not essential, we used a new questionnaire to acquire information. It has been divided into six sections which represent distinguishable sources (or dimensions) of occupational stress, including all those events now universally accepted $[7,15,21,29,30]$. The details are illustrated in Table 2. Each dimension has been described by several items, mainly taken from the most useful validated questionnaires [6,11,21-24]. Known elements are matched with more technical ones, largely incorporating items that were already proposed in previous questionnaires but also considering modern aspects of work-related stress.

Table 2. Sources (dimensions) of work-related stress, related issues included in the questionnaire and principal component analysis (PCA) reduction of number of items

\begin{tabular}{|c|c|c|c|}
\hline Dimension & Overall description & Item contents & PCA reduction \\
\hline Role & $\begin{array}{l}\text { personal work responsibilities and tasks to } \\
\text { meet company organizational, functional and } \\
\text { productive expectations for the job }\end{array}$ & $\begin{array}{l}\text { - autonomy } \\
\text { - role clarity, assigned objectives, } \\
\text { organizational model } \\
\text { - contribution to objectives in terms of } \\
\text { efficacy and productivity } \\
\text { - role innovation }\end{array}$ & $\begin{array}{l}\text { from } 14 \text { to } 6 \text { items } \\
\text { preserved variance } \\
=82 \%\end{array}$ \\
\hline $\begin{array}{l}\text { Structure } \\
\text { and climate }\end{array}$ & $\begin{array}{l}\text { main features of work, internal organization } \\
\text { and working environment }\end{array}$ & $\begin{array}{l}\text { - working hours } \\
\text { - safety and adequacy of working } \\
\text { conditions } \\
\text { - activities and task planning } \\
\text { - workload and rhythm }\end{array}$ & $\begin{array}{l}\text { from } 25 \text { to } 10 \text { items } \\
\text { preserved variance } \\
=79 \%\end{array}$ \\
\hline $\begin{array}{l}\text { Growth and } \\
\text { sensibility }\end{array}$ & $\begin{array}{l}\text { company management of human resources } \\
\text { in terms of professional growth, career } \\
\text { development, respect for differences (gender, } \\
\text { age, origin), sense of belonging and mission } \\
\text { sharing }\end{array}$ & $\begin{array}{l}\text { - system to acknowledge results } \\
\text { - company identity and sense of belonging } \\
\text { - internal business communications } \\
\text { - sensibility for differences }\end{array}$ & $\begin{array}{l}\text { from } 29 \text { to } 13 \text { items } \\
\text { preserved variance } \\
=84 \%\end{array}$ \\
\hline $\begin{array}{l}\text { Interpersonal } \\
\text { relationships }\end{array}$ & $\begin{array}{l}\text { features and types of relationships between } \\
\text { people on the job, both horizontal (colleagues) } \\
\text { and vertical (superiors), and group } \\
\text { relationships }\end{array}$ & $\begin{array}{l}\text { - relationships between colleagues } \\
\text { - relationships with superiors } \\
\text { - cooperation and team-work }\end{array}$ & $\begin{array}{l}\text { from } 21 \text { to } 11 \text { items } \\
\text { preserved variance } \\
=85 \%\end{array}$ \\
\hline Work/life balance & $\begin{array}{l}\text { management of work/life balance, i.e. } \\
\text { interactions between work and private life, } \\
\text { and the features of the balance itself }\end{array}$ & $\begin{array}{l}\text { - features of work/life balance } \\
\text { - opportunity to achieve and maintain the } \\
\text { desired balance } \\
\text { - interference of work with privacy } \\
\text { - family and social support }\end{array}$ & $\begin{array}{l}\text { from } 13 \text { to } 7 \text { items } \\
\text { preserved variance } \\
=76 \%\end{array}$ \\
\hline Fulfillment & $\begin{array}{l}\text { factors intrinsic to the job focusing on quality, } \\
\text { satisfaction and commitment at work }\end{array}$ & $\begin{array}{l}\text { - energy and dynamism } \\
\text { - involvement and motivation } \\
\text { - social integration }\end{array}$ & $\begin{array}{l}\text { from } 19 \text { to } 9 \text { items } \\
\text { preserved variance } \\
=78 \%\end{array}$ \\
\hline
\end{tabular}


Particular reference has been made to accredited Italian studies based on the above-described model, developed at the 2nd Faculty of Psychology, Rome University "La Sapienza" and promoted by the Ministry for Public Administration and Innovation of the Italian Government (www. magellanopa.it) [30,31].

Occupational stress connected to work content, work environment and features related to change were investigated with explicit reference to specific aspects, such as employee-company reciprocity, employee support by personal relationships and the community outside work, enterprise responsiveness to social differences (gender, age, origin), public transport and childcare availability. Ten new items were formulated in order to take into account recent developments in the world of work. They concern the commitment and devotion to work, employees' own perception of their quality of life, interactions with the current economic crisis, the major problems of social integration and stressors outside of work.

The items were included into the questionnaire using the Delphi method in which some expert psychologists, doctors, economists and entrepreneurs periodically convene to supply a stepwise updating of validated existing questionnaires [32]. In particular, the method allowed us to reach a shared version of the questionnaire by consulting four members of the Italian academic world, one leading exponent of the sanitary local agency and the entrepreneur of a major company in Tuscany.

Only job-related behavioral and socio-economic aspects, subjectively perceived by workers, were included in the questionnaire. Therefore, the questionnaire did not include individual specific questions about objective physical and mental illness and therapies.

The primary version of the questionnaire included 137 items, 121 of which belonged to the above six dimensions and 16 concerned extra-occupational aspects, such as sex, age, family composition and so forth, to complete the employee's profile.
All items were expressed as a statement to be evaluated on a Likert scale of ten discrete levels (1-10) of agreement. Use of the same scale allowed standardization of information, making the statistical multivariate analysis more simple and reliable [33].

The questionnaire was shortened using the principal component analysis (PCA). The number of items was reduced as much as possible, by preserving at least the $80 \%$ of explanatory power. For this purpose, the questionnaire was first administered to an additional smaller cohort of 414 cases without regional stratification. For each stress dimension, PCA was performed by rotating the solutions with Varimax method and Kaiser normalization [34], in order to obtain as small as possible subset of items giving approximately $80 \%$ explanation of total variance (Table 1). This allowed unnecessary redundancies due to correlations between items to be eliminated, while leaving almost unchanged the information content, resulting in the fundamental advantage of a simpler, cheaper and faster administration of the questionnaire to the employees by telephone interview.

The items of the shortened questionnaire have been included in the Appendix. It was administered during 2010 by telephone interviews to the stratified sample of 2419 employees. The method of Computer Assisted Telephone Interviews was used by Microcosmos call center of Siena (Italy), limiting individual interviewing time to 10-15 minutes. The procedure was carried out under the current Italian law on informed consent and the protection and processing of personal and sensitive data. People who refused to undergo the interview were replaced by individuals with the same statistical strata.

\section{Risk scores}

A score for each of the six stress dimensions (see Table 2) was created to provide a useful characterization of the different types of stress perceived by employees. Risk scores were obtained by a multivariate statistical procedure that 
sequentially combined a classical supervised clustering technique with the linear discriminant analysis [35], as follows:

- non-hierarchical cluster analysis by the centroid method with two clusters initialized at polar centroid values, 1 and 10, to represent extreme conditions of null or maximum item-associated stress;

- interpretation of final clusters as realistic opposite stress conditions; if not, restart the process at different initialization values;

- multivariate linear discriminant analysis of final clusters with the dimension items as covariates;

- assumption of the linear discriminant function as risk score, expressed as a percentage of the whole score range.

The six risk scores so obtained were used as descriptors for a wider and more articulate interpretation of the individual stress profile. In agreement with the more recent and authoritative literature, they are identified to characterize important dimensions of occupational stress, at a higher level than single items. For each dimension, a one-dimensional scale (or score) was created to discriminate low from high risk of stress, as reliably as possible. The above-described statistical procedure leads to two fundamental advantages over the commonly-used methods which simply average items' responses: the contribution of each item to the score is naturally weighted by its empirical discriminant importance; biases due to different mutual correlations among items are thus avoided.

\section{Model planning}

The proposed causal model is based on the definition of work-related stress by the European Agency for Safety and Health at Work [18]: "Work-related stress is experienced when the demands of the work environment exceed the workers' ability to cope with (or control) them", and agrees with the theoretical foundation of work-related stress [1-6] and most accredited updates in recent literature [7-10,14,16,17,22].

The model incorporated three classical aspects, named axes, for interpreting the causal links of occupational stress, for the first time introduced by Karasek [3], later revised by Johnson and Hall [5], and Karasek and Theorell [6]: Demands (D), Responsiveness/Control (R) and Support (S).

They have been described reconsidering all the questionnaire items and classifying each of them in only one of these three aspects, through careful psychosocial and economic evaluation which still involved Delphi group [32]. The aim was mostly reached by using the existing coding of analog items of commonly used validated questionnaires [6,11,21-24]. However, independently from the existing code, experts were encouraged to give their free contribution because of well-known problems associated with lack of empirical support able to confirm the theoretical interaction between job control and job demand [25]. Item memberships to both six dimensions of stress and three model axes are specified in the Appendix. A range of measurements for $\mathrm{D}$ wider than that identified by the classical approach of Karasek has been given [3]. Moreover, the support scale, S, which had been proven to contribute much to the Karasek model, was extended to external factors connected with the social integration and the quality of private life.

Because the items of each axis were selected by following a non-statistical procedure, Cronbach's $\alpha$ analysis was performed to test their statistical consistency and reliability [36]. A one-dimensional quantitative description of each aspect was obtained using the same clustering approach as for risk scores, that is by maximizing the discrimination level between low and high values of $\mathrm{D}, \mathrm{R}$ and $\mathrm{S}$, detected by empirical data through non-hierarchical cluster analysis. Specifically:

- axis D (Demands) expressed the demands of work and employer's instructions; 
- axis R (Responsiveness/Control) described the degree of worker control of individual work (mastery, command, autonomy, competence) as an expression of capacity to respond to employer's demands;

- axis S (Support) defined the support received at and outside work, as an element of stress abatement.

The interpretation of model axes allowed us to identify three important cause-and-effect relationships (or stress states) representing different balances among perceived D, R and S:

- well-being or beneficial stress (eustress): sufficient stimulus for fruitful work, perception of balanced demands, responsiveness and support; eustress is indicated by similar medium-high scores of all three axes;

- excessive stress (distress); demands exceed worker capacity to respond adequately, including individual control and external support; distress is indicated by medium-high scores of axis D and significantly lower scores of axes $\mathrm{R}$ and $\mathrm{S}$;

- demotivation or inefficiency: low and/or inadequate demands and support leading to poor worker responsiveness due to apathy/boredom, lack of stimulation, or incompetence; this condition is indicated by low scores of all three axes.

To identify the groups of workers clearly belonging to the three stress states, we applied a hierarchical divisive cluster analysis (centroid technique), in the three-dimensional space of model axes. The procedure is arrested when a sufficient number of clusters, representing at least $5 \%$ of the training sample for each stress state, are formed.

We represented well-being in the workplace not as absence of stress, but as the stress level providing appropriate incentive to work (optimum or eustress); the other two states (distress and lack of motivation) were on the opposite sides of the optimum, caused by excessive and insufficient demands, respectively.

Linear discriminant analysis was applied to the axis scores to find the two discriminant functions, $\mathrm{f}_{1}$ and $\mathrm{f}_{2}$. They provide optimal linear separation between each pairs of the three empirically-identified clusters of workers representing the three modeled stress states. In other words, $\mathrm{f}_{1}$ and $\mathrm{f}_{2}$ define two discriminant dimensions that allow the best distinction between homogeneous groups of different actual perceptions about occupational stress by Italian employees. A parabola, having a turning-point coinciding with the well-being centroid and passing through the distress and demotivation centroids, provided a one-dimensional nonlinear description of stress (Figure 1). We then calculated a stress index (SI), equal to the positive or negative curvilinear distance from the turning-point (zero value), for distress and demotivation, respectively. In the two-dimensional space $\mathrm{f}_{1}-\mathrm{f}_{2}$, workers could therefore be associated with a stress value corresponding to the nearest point on the parabola. The parabola, the curvilinear distance from its vertex and the projection of points on it, were calculated through familiar analytical procedures, i.e. by solving a linear system, performing a curvilinear integration and searching for a relative minimum, respectively.

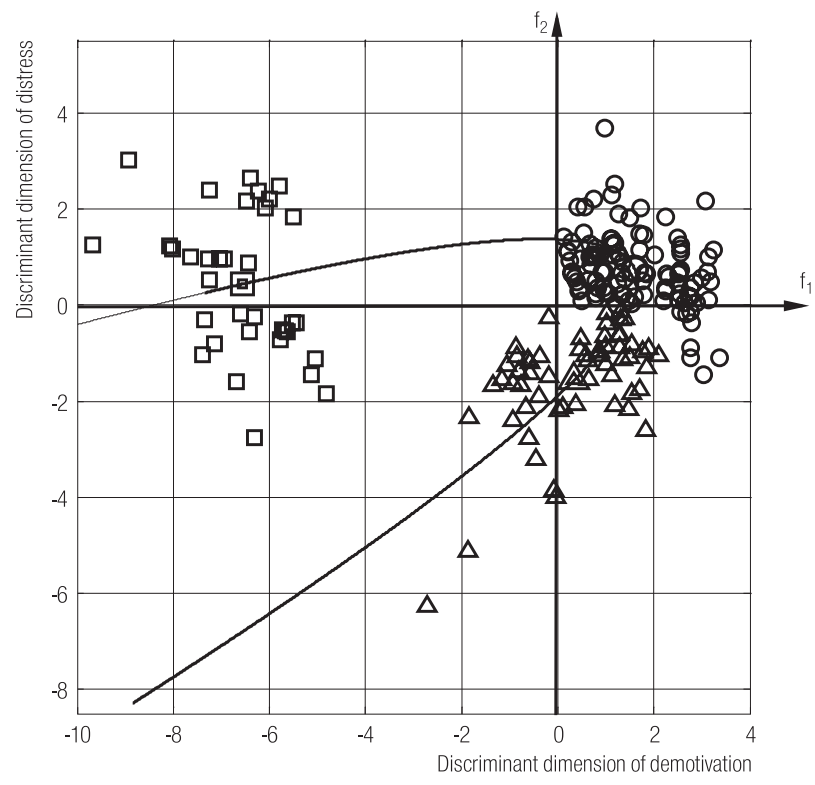

Larger symbols indicate group centroids.

Fig. 1. Parabola of work-related stress model with scatterplot of testing data 
Non-productivity costs were evaluated by linear rescaling of the stress index to obtain a mean absolute value equal to the cost per employee of work-related stress in the United Kingdom (UK), estimated in 2007 from a study commissioned by the UK government. Since no Italian data were available, we therefore reasonably assumed that Italy and UK workers had comparable costs for stress. Finally, the following exponential transformation was conveniently used to express SI in values similar to human systolic arterial pressure:

$$
\mathrm{SM}=\beta_{0} \mathrm{e}^{\beta_{1} \mathrm{SI}+\beta_{2} \mathrm{SI}^{2}}
$$

where:

$\mathrm{SM}$ - stress manometer,

$\beta_{0}, \beta_{1}$ and $\beta_{2}$ - constants that define the exact association between the SI values of each centroid and the corresponding pressure values in $\mathrm{mmHg}$,

SI - stress index.

In particular, we arbitrarily selected $90 \mathrm{mmHg}$ (arterial hypotension), $120 \mathrm{mmHg}$ (physiological pressure) and $150 \mathrm{mmHg}$ (arterial hypertension) in correspondence with demotivation, well-being and distress centroids, respectively. Beta coefficients were analytically determined by imposing the three above conditions and then solving a simple linear system of three equations in three unknowns, derived from the logarithmic transformation of equation (1). Through the transformation of equation (1), the various levels of distress and demotivation were associated to values of human blood pressure which, though arbitrary, reflect actual pathophysiological values. The stress index, rescaled to human systolic arterial pressure values, allowed undesirable stress conditions to be associated with circulatory system anomalies: hypotension is associated with debilitating fatigue and hypertension with circulatory overload. This parallel provides an immediate interpretation of individual stress risk, even for non-experts (e.g. entrepreneurs and managers), linking stress with heart symptoms $[5,12,13]$.

\section{RESULTS}

A refusal rate for telephone interviews of $72 \%$ was observed, so that a total of 8639 telephone contacts were needed to complete the stratified sample of 2419 Italian employees. It took two months.

Proportional stratification of all Italian workers allowed us to reduce considerably sample size and error. The $95 \%$ confidence interval of sampling error, estimated by the bootstrap technique, was less than $2 \%$ of the whole variation range of stress index.

We have not built the questionnaire from scratch but we have preferred to incorporate a priori knowledge to represent the sources of stress already identified by the most accredited model applied in Europe [7,15]. The items have been created mainly by collecting them from other questionnaires $[21,22,30]$, by involving experienced sociologists and psychologists in the choice through Delphi method [32]. This allowed us to use a questionnaire with content and structure already widely validated by a psychosocial point of view.

PCA reduced the number of questionnaire items from 121 to 56, preserving about $81 \%$ explained variance of the whole phenomenon. The details of PCA are reported in Table 2. In particular, the new ten items included in the primary extended questionnaire were reduced to 4 in the final questionnaire (see Appendix 1).

The stratification of Italian population by gender, economic field of activity and region enabled national benchmarks of the current occupational stress condition to be evaluated simply by averaging the results of the workers belonging to each category. So, for example, we could obtain the Italian benchmarks of male employees, workers employed in hotels and restaurants, northern Italy workers, and so on (results not reported).

Cronbach analysis proved high reliability of the model axes, confirming the good selection of Delphi group. The analysis suggested just a little adjustment to improve statistical reliability, so that only five unnecessary or confusing 
items were discarded (see Appendix). Specifically, we obtained: $\alpha_{\mathrm{D}}=0.873$ (17 items); $\alpha_{\mathrm{R}}=0.848$ (18 items); $\alpha_{\mathrm{S}}=0.765$ (16 items).

Hierarchical cluster analysis in axis space stopped at 30 clusters, of which four, three and four were recognized to represent demotivation (5\% of training data), well-being $(17 \%)$ and distress (10\%), respectively. Figure 1 shows the stress parabola, in which demotivation was discriminated better from well-being than was distress. The scatterplot of testing data, closely clustered around the corresponding training-data centroids, proved good model performance. The model, based on training sample data, supplied values of the stress index (SI) equal to $-4.85,0$ and 2.25 , in correspondence with demotivation, well-being and distress centroids, respectively. Beta coefficients in equation (1) can be therefore calculated by substituting these SI values together with their respective SM values, that is 90,120 and $150 \mathrm{mmHg}$. The solution of the associated linearized system gave: $\beta_{0}=120, \beta_{1}=0.08654$ and $\beta_{2}=0.00561$.

Under the hypothesis of equal distribution for responders and non-responders, the lack of any statistically significant differences between training and testing data for the stress index (Mann-Whitney test, $\mathrm{p}=0.897$ ) indicated good model generalization capacity. Median and interquartile values (in brackets) were $0.133(-1.363-0.853)$ and 0.035 (-1.097-0.875), respectively.

Figure 2 illustrates the representation of work-related stress in terms of human systolic arterial blood pressure through an example related to an actual manufacturing wood company of 80 employees, located near Florence. It shows that the stress manometer (SM) has a low value if compared to the other companies that belong to the same economic field of activity and compared also to the national benchmark (Italy). Both manufacturing wood companies and the whole national sample show optimal SM benchmarks. People working in that exemplified company are on average less engaged/involved/ committed and more demotivated than both workers of all the other manufacturing wood companies and all Italian employees.

Table 3 shows estimated risk and percentage axis scores for the three centroids of stress states and their national averaged values. "Growth and sensibility" and "Work/ life balance" obtained the highest mean national scores (40\% and $41 \%$, respectively), while "Structure and climate" and "Fulfillment" had the lowest national values (28\% and 29\%, respectively), although a wide variability was always found (SD around 20\%). All risk scores took consistently low values in the well-being state and high values in the demotivation state. The distress state had slightly higher values than well-being but only in four dimensions (nos. 3-6), confirming the less clear-cut separation between these two states. Therefore, it was necessary

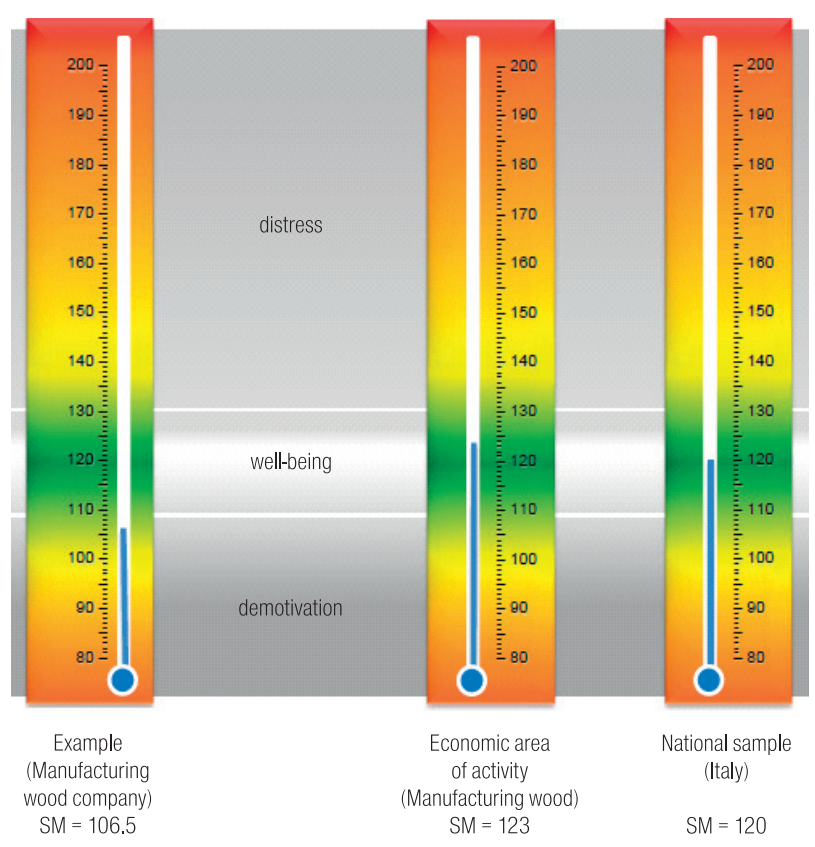

Stress manometer (SM) is the nonlinear one-dimensional representation of work-related stress in terms of human systolic arterial pressure. Green and red colors indicate conditions of well-being and stress, respectively.

Fig. 2. Stress index on a manometer: example of a manufacturing wood company (near Florence, 80 employees) compared with the benchmarks of the same economic field of activity and of the whole Italian sample 
Table 3. Mean (cluster centroid) and standard deviation (SD) of percentage model scores for the three stress states in the whole Italian employee sample

\begin{tabular}{|c|c|c|c|c|c|c|c|c|c|c|}
\hline \multirow[t]{2}{*}{ Stress states } & \multicolumn{6}{|c|}{$\begin{array}{c}\text { Risk scores } \\
\text { mean (SD) } \\
(\%)\end{array}$} & \multicolumn{3}{|c|}{$\begin{array}{c}\text { Axis scores } \\
\text { mean (SD) } \\
(\%)\end{array}$} & \multirow[t]{2}{*}{$\begin{array}{c}\text { Stress } \\
\text { manometer }\end{array}$} \\
\hline & 1 & 2 & 3 & 4 & 5 & 6 & $\mathrm{D}$ & $\mathrm{R}$ & $\mathrm{S}$ & \\
\hline Distress & $20(14)$ & $15(11)$ & $33(16)$ & $29(14)$ & $44(19)$ & $25(12)$ & $83(8)$ & $61(16)$ & $65(11)$ & $\int_{130 \mathrm{mmHg}}^{150}$ \\
\hline Well-being & $20(12)$ & $16(12)$ & $23(9)$ & $15(10)$ & $32(20)$ & $21(12)$ & $79(8)$ & $77(7)$ & $81(7)$ & $\underbrace{120}_{110 \mathrm{mmHg}}$ \\
\hline Demotivation & $69(21)$ & $66(17)$ & $83(9)$ & $79(14)$ & $59(26)$ & $48(23)$ & $25(11)$ & $19(10)$ & $17(9)$ & 90 \\
\hline $\begin{array}{l}\text { Averaged } \\
\text { value (Italy) } \\
\end{array}$ & $32(23)$ & $28(20)$ & $40(22)$ & $32(21)$ & $41(23)$ & $29(17)$ & $59(21)$ & $67(21)$ & $64(20)$ & \\
\hline
\end{tabular}

1 - role; 2 - structure and climate; 3 - growth and sensibility; 4 - interpersonal relationships; 5 - work/life balance; 6 - fulfillment.

D - demands; R - responsiveness/control; S -support.

* Stress manometer is the nonlinear one-dimensional representation of work-related stress in terms of human systolic arterial pressure.

to consider also the axes values for a correct interpretation of increasing risk of stress. Distress was associated with greater demands (83\%) and significantly lower responsiveness $(61 \%)$ and support (65\%) than well-being, while demotivation was clearly characterized by very low scores for all axes.

A careful interpretative analysis of Table 3 shows that distress occurs when workers are unable to respond adequately to increased perceived demands $(\mathrm{D}>\mathrm{R})$, principally due to deteriorating opportunities for professional growth (dimension no. 3), interpersonal relationships on the job (dimension no. 4) and work/life imbalance (dimension no. 5, D > S). On the other hand, a demotivated employee perceives few demands (lack of stimuli) and is not encouraged to produce due to lack of support (low S), inexperience, ineptitude or demands that go beyond his/her professional duties (low R); she/he tends to interpret anything related to work negatively (all high risk scores).
A suggestive representation of the stress index in the three-dimensional space Demand-Responsiveness/ Control-Support is shown in Figure 3. The surface was obtained by fitting a feed-forward neural network to our sample data and describes stress index by colors that are consistent with Figure 2. Figure 3 allows the observation of actual causal links of stress existing in the population of Italian workers, and the immediate identification of stress perceived by an employee (or a company, as the average of its employees) with its respective causalities, through its placement on the diagram. Demotivation occurs when all the three axes are at low values, while distress arises when support is low and at the same time demand is so high that the worker does not succeed to respond adequately. Asterisk indicates the position of the company example reported in Figure 2. We can note its location in an area just below the optimal area (darker green).

Figures 2 and 3 and Table 3 supply a comprehensible identification of the stress condition of each worker or each 


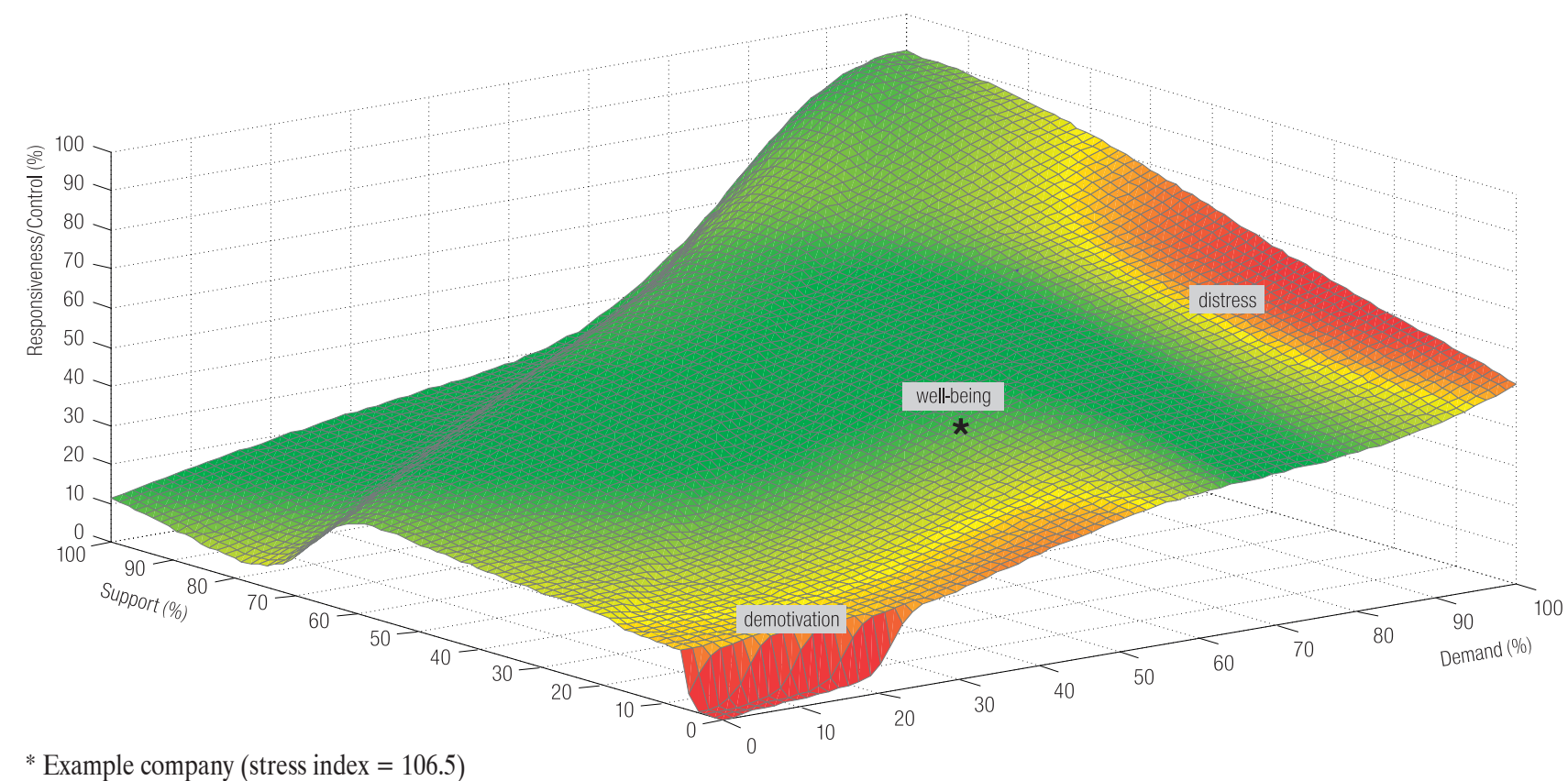

* Example company (stress index $=106.5$ )

Abbreviations as in Figure 2.

Fig. 3. Three-dimensional representation of work-related stress according to the Demand-Responsiveness/Control-Support model

company, by workers' averaging. It can be easily recognized and interpreted by the following hierarchical investigation:

- First we calculate SM index in order to classify stress in one of the three states (demotivation, well-being or distress) and to evaluate its strength on the basis of color types and ranges given in Figures 2 and 3. The green range in the manometer of Figure 2, approximately between 105 and $135 \mathrm{mmHg}$, indicates wellbeing, while demotivation and distress are clearly recognizable below $100 \mathrm{mmHg}$ and over $140 \mathrm{mmHg}$, respectively: high levels of both demotivation and distress are represented by red colors, reached by passing through yellow and orange colors.

- Secondly, we examine axes' values to interpret the causal relationships, with assistance from Figure 3 and Table 3.

- Then, we consider dimension scores as descriptors to evaluate the different types of stress risk and to understand better the reasons for the SM-identified stress condition.
- Finally, single items of the questionnaire related to higher risk factors could be explored for in-depth analysis, in order to develop the best possible strategies for correction of individual stress. To this aim, when the evaluation of occupational stress is directed to employees of a company as a whole, and not to a single worker, the procedure can be continued with the application of multivariate regression techniques [35] to identify the risk factors and/or the items most responsible for the stress condition of workers, thus suggesting the directions of the company improvement, as the balance between required performance indicators and welfare of workers.

The above described procedure for the detection and interpretation of perceived work-related stress can be better understood through the detailed description of two actual examples. The first example is related to a strongly-demotivated public employee woman, taken from our national sample and arbitrarily named "Maria"; the second 
example refers to the manufacturing wood company mentioned above (Figure 2).

By applying our model to the questionnaire data of Maria, we obtain $\mathrm{SM}=60 \mathrm{mmHg}$ which immediately indicates a clear state of deep demotivation (see also Figure 2). Maria experiences a poor job demand $(\mathrm{D}=17 \%)$ and a very low support $(\mathrm{S}=6 \%$ ) but she feels able to master harder situation $(\mathrm{R}=25 \%)$. All the associated risk scores are very high (more than 50\%) reaching the $100 \%$ for the first stress risk dimension (Role) which indicates a total role confusion. In particular, Maria attributed the maximum Likert-scale level of 10 to the questionnaire item "I can easily complete my daily assignments". This confirms a worker responsiveness greater than that requested and makes explicit her lack of motivation.

For what concerns the second example of the manufacturing company of Florence, we omit the description of axes and dimensions of stress in order to focus on the last point of the procedure, about the identification of triggering factors of stress that, also in this case, occurs on average as demotivation. The multivariate regression analysis has shown that items nos. 2 ("I have a clear view of the role assigned to me"), 4 ("Company involves me on scheduled operational changes"), 37 ("Superiors evaluate the work of the staff in a clear way, explaining the ratings given") and 38 ("In our working group we feel members of a team") are the most related to employees' lack of motivation (about the $80 \%$ of explained variance). The first two items belong to the axis D and to the first dimension of stress risk (Role), while the last two items are included in the axis $\mathrm{S}$ and the dimension no. 4 (Interpersonal relationships). Score values for all these four items were low. Therefore, possible actions to reduce stress may be: to improve internal communication, to enhance the sense of belonging to the working group and to stimulate workers with some innovations in the workplace.

The described examples show how our model allows an efficacious analysis of questionnaire data to supply an easy

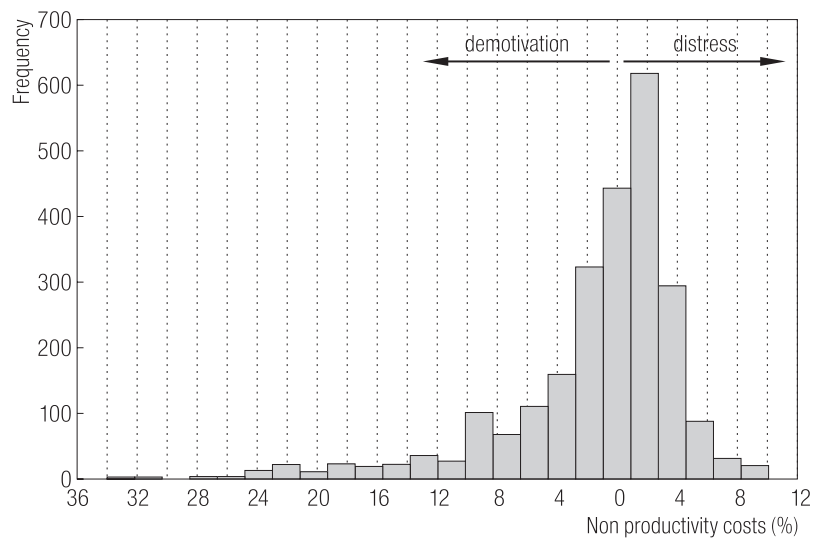

Zero represents optimal employee contribution to company production.

Fig. 4. Histogram of non productivity costs, expressed as percentage, due to demotivation (left of zero) and distress (right of zero) in the Italian employee sample

and exhaustive psychosocial interpretation of the occupational stress which can be completed with interventions to improve working conditions and the estimation of the economic consequences of stress.

Figure 4 shows the histogram of estimated economic loss due to reduced employee productivity caused by occupational stress, as a percentage of company income from employment. The distribution extends more towards demotivation (left) than distress (right), reaching inefficiencies of $34 \%$ (Maria). The mean cost is $3.7 \%$ which corresponds to $1.6 \%$ of the Italian gross domestic product (GDP). In the company example, unproductive costs for demotivation are $5.6 \%$ of total company expenses for salaries, which means $50 \%$ higher than the national average.

\section{DISCUSSION}

In 1930, the concept of stress was introduced for the first time in physiology by Hans Selye, who defined it as a nonspecific physiological response of the body to any pressure or demand [1]. Since then, abundant literature in the psychosocial sciences and medicine has appraised the concept 
and applied it to occupational situations [7], developing various interpretative models [3-6].

It is now generally accepted that prolonged stress leads to illness and reduces working efficiency. For example, highly stressed employees have been shown to be at significantly higher risk of cardiovascular disease [12,13,37].

Nowadays, international community are dedicating much attention to workplace stress, which is growing because of new practices such as outsourcing, role and function flexibility, temporary contracts, less job security and higher workloads [15-18].

Taking into account both the established classical aspects of work-related stress, and some new aspects related to recent changes that occurred in the world of work, we have proposed an approach quite different from existing ones, for the reliable measure of the stress that the workers perceive today. To this aim, we have designed a model based on the theoretical foundations of occupational stress [1-4] and incorporating reliable recent notions on the subject $[6-8,10]$. In particular, we largely referred to the demand-control model of Karasek [3], which was successively updated with the introduction of job support scale by Johnson and Hall [5], and then further revised. The Demand-Control-Support (DCS) model is one of the most popular models employed to describe the psychological and socioeconomic aspects of occupational stress perceived by workers which has been discussed and tested for many years. Accordingly, in this study we interpret the causal links of stress through employee perception of imbalance between demands (stress to produce, workload, etc.) and resources to respond appropriately to job demands (mastery, autonomy, collaboration, human and technological support, etc.). Several improvements or adaptations have been made to DCS model to overcome some problems related to evident discrepancies between theoretical assumptions and empirical results [25].

In particular, in agreement with important innovative advances in the field [5-7,11,15-18,21], we have considered a greater number of measures to be associated with the demand scale and enriched the job support scale, which has been proven to contribute significantly to model performance [6], with aspects inherent to private life and social integration.

The effort to build a new questionnaire representative of the studied aspects of occupational stress (instead of using one of already available questionnaires) [6,11,21-24] was primarily motivated by the aim to optimize the statistical analysis. In particular, since the study was directed to the whole population of Italian employees, we wanted to avoid a questionnaire already built for other population that might be less reliable on representing Italian reality. It is well-known that, in order to extend the sample results to the reference population, an effective customization of the instrument for data collection is very important. The effective exportability of any model to scenarios and times different from those in which the model was designed is a critical and controversial point and often leads to a substantial reduction in the result accuracy [26,38]. For this reason, in the definition of the items of our questionnaire, we are mainly referring to recent major Italian studies [30,31]. Therefore, when socio-economic phenomena as complex as work-related stress are studied over large populations, we believe it is necessary to optimize all the statistical tools applied. In this regard, though item response theory (IRT) is often preferred for the reduction of the number of items [39], we opted for the classical principal component analysis because our intention was to reduce the time of questionnaire administration as much as possible, while preserving the most of global information [35]. On the contrary, IRT is more focused on item information [39]. Moreover, IRT generally requires large sample sizes and needs stronger assumptions than classical test theory, and this is in contrast with our data [40,41]. Anyway, we want to strongly emphasize that it was not our intention to propose a new questionnaire and validate it. Indeed, our approach can be applied, with only a few 
simple adjustments, to any other questionnaire, existing or to be created, or even suitable for different socioeconomic studies.

Our aim was to provide a quantitative measurement of occupational stress as accurate and reliable as possible for the specific population of Italian employees at the current time. Generally, model approaches for the evaluation of perceived work-related stress from questionnaires did not pay much attention to the methods for creating the scales of measurement, often merely adding up item scores. The lack of an optimization criterion for the scoring can lead to a serious deterioration in the performance of the model, even to the extent of causing that it is no longer valid.

The most of methods for the analysis of questionnaire data derive scores from item explained variance. In multivariate statistics, it is known that the maximization of the explained variance of a phenomenon does not coincide with maximizing the discrimination of some interesting patterns of the phenomenon itself [35]. Therefore, scores based on the variance maximization may easily fail to detect basic characteristics that identify important actual aspects of the studied phenomena. Instead, our method finds scores that have just the highest discriminant power to distinguish differences between interesting patterns (detected by the cluster analysis) that describe opposing aspects truly representative of the empirical data, such as low and high stress risk conditions. The recognition of two clusters with opposite stress risks for each of the six stress risk dimensions (Table 2), and subsequent linear discriminant analysis, identified the discriminant function as the best one-dimensional representation for maximizing separation between contrasting features and capturing real distinctions of stress risk perceived by workers. Compared to the usual practice of making simple sums of item scores (sometimes weighted empirically), the proposed clustering approach has the important advantage of not being influenced by different levels of correlation between items. This significantly improves the reliability of results.

The six dimensions of stress risk were introduced for purely descriptive purposes. In agreement with recent and accredited studies of the European community, they represent descriptors, at a higher level than single items, to characterize the sources (or dimensions) of occupational stress [15-18]. For each dimension, a one-dimensional scale was created to discriminate low from high risk of stress, as exactly as possible. The use of these six risk scores allowed a more accurate interpretation of stress condition by completing the causal analysis of model axes Demand, Responsiveness/Control and Support.

The stress index identified by the DRS axes was able to give a reliable characterization of the whole phenomenon of work-related stress with a single non linear dimension able to discriminate as exactly as possible between occupational demotivation, well-being and distress. We, therefore, modeled work-related stress in terms of two adverse conditions separated from well-being (favourable stress stimulating productive work, or eustress), as described in specialist literature where this non linear behavior is cited as "inverted U pattern" $[42,43]$. Consequently, we have represented employee motivation, well-being and distress by a parabola having its vertex in the well-being condition, matching the stress index in zero. The motivation and distress were associated with negative and positive values of stress index, respectively (see Figure 1).

We decided arbitrarily to select a representation of stress values in term of human systolic arterial pressures because it allows the level of stress to be expressed through a direct association with its pathophysiological consequences, as it is known from the literature that high levels of stress affect the cardiovascular system, causing arterial pressure changes $[5,12,13]$. Nowadays, people have become familiar with blood pressure values expressed in terms of $\mathrm{mmHg}$. Therefore, we found it simple and intuitive to associate high stress conditions (or distress) with hypertension, low 
motivation with hypotension and well-being with normal arterial pressure values. Moreover, this analogy is particularly useful to appropriately describe the bipolar nature of the stress that is located at the two ends of a non-linear scale where well-being is in the middle.

Another important problem that arises when we attempt to give a measure of a subjective quantity is the need to identify points of reference to which the measurement is compared. Actually it is not so important to know the absolute value of stress, but, for example, whether it is higher or lower than the average of all employees, or than the employees of the same working activity. Our statistical approach, based on a sampling strategy that collects empirical data, representative of homogeneous stratified groups of the whole population of Italian employees, allowed us to define precise and reliable benchmarks referring to gender, geographical area and economic field of activity.

Impairment of physical and mental faculties of employees inevitably impairs the performance of the organization, increasing absenteeism and staff turnover and decreasing productivity. The current economic crisis is also demonstrating an increase in presenteeism, when employees go to work despite illness and unfitness to carry out their duties. Presenteeism is common with mentally ill employees who respond to problems with fear, anxiety and excessive insecurity [19]. A recent study in the United Kingdom showed that the cost of lost productivity due to work-related stress was $£ 25900000$ thousand in 2007, about $1.9 \%$ of gross domestic product (GDP) [20,44]. Since no such studies exist about the Italian population, we reasonably assumed that demotivation and distress in Italian employees had similar costs per capita, leading to a total of $€ 24200000$ thousand, i.e. $1.6 \%$ of the Italian GDP that in 2010 was equal to $€ 1548816180$ thousand [45]. Since only about $42 \%$ of GDP is generated by employees, stress costs on average $3.7 \%$ of national income from employment (Figure 4).
A reliable measure of work-related stress is nowadays essential and can be an effective tool available to psychologists, sociologists, occupational physicians, employers, so they can better target their investigations and optimize their intervention strategies. To this aim, posterior statistical investigations, such as descriptive reports, meta-analysis and stepwise regression analysis, can help to identify significant items and stress risk dimensions most relevant to distress and demotivation $[27,33]$.

\section{Limitations}

The sample survey was conducted via telephone interview. This method may be different from that used in some companies and institutions, in which the survey may occur by direct administration. Of course, the validity of our model strictly depends on the hypothesis of equal distribution for our questionnaire data and other data derived from different collection methods or missing data, such as those related to non-responders. Although the interviews were conducted by professional experts able to avoid as much as possible exerting a psychological influence on the responses of the interviewee, a precise assessment of the possible bias introduced, and its eventual correction, could be made only through sample designs that statistically compare the results obtained with different detection techniques.

The optimization of statistical procedures based on national benchmarks involves necessarily a periodic revision of data samples. Therefore, subsequent sample surveys need to follow the dynamic changes of the phenomenon and allow benchmarks to be updated.

Compared to traditional methods where summative scores are often simply calculated without a computer, a more complex computational effort is necessary to assess our model quantities, i.e. the stress index and manometer readout, dimension scores and axes. However, the described methods are easily implementable on the most common mathematical and statistical software in commerce, spreadsheets included. 


\section{CONCLUSIONS}

Our method is able to supply a reliable and articulate quantitative characterization of perceived occupational stress which can be easily interpreted and compared with national benchmarks. Thus, it allows the planning of targeted corrective and preventive actions to normalize stress at work and increase human performance.

Fighting demotivation by promoting job satisfaction is a valuable policy for promoting sustainable economic growth. Loss of company productivity due to employee distress, demotivation and inefficiency can be estimated and quantified by our proposed model. The whole procedure of work-related stress measurement and identification is applicable to any type of firm, public or private, and any field of activity. In the current international structural economic crisis, where motivation and development of human resources plays a key role, the reliability of this kind of measures can be crucial.

\section{ACKNOWLEDGEMENTS}

The authors would like to thank Costanza Consigli, Cristina Faini and Giovanni Iozzi for their expert technical support. The work was in part supported by research funds (PAR) of the University of Siena.

The authors Roberto Gambassi and Ilaria Fratini sometimes use the method described in the manuscript for academic and professional consultancy.

\section{REFERENCES}

1. Selye H. The stress of life. New York: Mc Graw-Hill; 1976.

2. Cooper CL, Marshall J. Occupational sources of stress: a review of the literature relating to coronary heart disease and mental ill health. J Occup Psychol 1976;49(1):11-28.

3. Karasek RA. Job demands, job decision latitude, and mental strain. Implication for job redesign. Adm Sci Q 1979;24(2): 285-308.
4. French JRP, Caplan RD, Van Harrison R. The mechanisms of job stress and strain. New York: Wiley; 1982.

5. Johnson JV, Hall EM. Job strain, work place, social support, and cardiovascular disease: a cross-sectional study of a random sample of the Swedish working population. Am J Public Health 1988;78:1336-42.

6. Karasek RA, Theorell T. Healthy Work: Stress, Productivity, and the Reconstruction of Working Life. (Appendix I). New York: Basic Books; 1990.

7. Cooper CL. Handbook of stress, medicine and health. New York: CRC Press; 1996.

8. Cox T, Griffiths A, Barlowe C, Randall R, Rial-Gonzalez E. Organizational interventions for work stress: A risk management approach. Sudbury, United Kingdom: HSE Books; 2000.

9. Maslach C, Leiter MP. Burnout and engagement in the workplace: A contextual analysis. In: Urdan TC, editor. Advances in Motivation and Achievement. United Kingdom: Stratford Books; 1999. p. 275-302.

10. Dewe P, Leiter MP, Cox T. Stress, coping, \& health in organizations. London: Taylor \& Francis; 2000.

11. Smith A. The scale of perceived occupational stress. Occup Med (Lond) 2000;50(5):294-8.

12. Byrne DG, Espnes GA. Occupational stress and cardiovascular disease. Stress Health 2008;24:231-8.

13. Eller NH, Netterstrøm B, Gyntelberg F, Kristensen TS, Nielsen F, Steptoe A, et al. Work-related psychosocial factors and the development of ischemic heart disease: A systematic review. Cardiol Rev 2009;17(2):83-97.

14. Potocka A. What do we know about psychosocial risk factors at work? Part I. Theoretical considerations. Med Pr 2010;61(3):341-52 [in Polish].

15. Cox T, Griffiths A, Rial-González E. Research on Work-Related Stress. Report of the European Agency for Safety and Health at Work. Luxembourg: Office for Official Publications of The European Communities; 2000 [cited 2011 Dec 15]. Available from URL: http://osha.europa.eu/en/publications/reports/203.

16. Parent-Thirion A, Fernández Macías E, Hurley J, Vermeylen G. Fourth European Working Conditions Survey. 
Report of the European Foundation for the Improvement of Living and Working Conditions. Luxembourg: Office for Official publications of the European Communities; 2006 [cited 2011 Dec 15]. Available from URL: http:// www.eurofound.europa.eu/ewco/surveys/EWCS2005/index.htm.

17. Brun E, Milczarek M. Expert forecast on emerging psychosocial risks related to occupational health and safety. European Agency for Safety and Health at Work. European Risk Observatory Report. Luxembourg: Office for Official Publications of the European Communities; 2007 [cited 2011 Dec 15]. Available from URL: http://osha.europa.eu/en/ publications/reports/7807118/view.

18. Milczarek M, Schneider E, Gonzalez ER. OSH in figures: stress at work - facts and figures. European Agency for Safety and Health at Work. European Risk Observatory Report. Luxembourg: Office for Official publications of the European Communities; 2009 [cited 2011 Dec 15]. Available from URL: http://osha.europa.eu/en/publications/reports/ TE-81-08-478-EN-C_OSH_in_figures_stress_at_work.

19. Sahler B, Dubois A, Journoud S, Pelletier J. Work in Tune with Life: A guide to the business case for mental health. Essen: BKK Bundesverband / ENWHP Secretariat; 2009 [cited 2011 Dec 15]. Available from URL: http://www.enwhp. org/fileadmin/downloads/8th_Initiative/MentalHealth_ Broschuere_businesscase.pdf.

20. Lelliott P, Tulloch S. Mental health and work. Report for the National Director for Work and Health. London: RCP; 2008 [cited 2011 Dec 15]. Available from URL: http:// www.workingforhealth.gov.uk/documents/mental-healthand-work.pdf.

21. Cooper CL, Sloan SJ, Williams S. Occupational Stress Indicator. Windsor, England: NFER-Nelson; 1988.

22. Williams S, Cooper CL. Measuring Occupational Stress: Development of the Pressure Management Indicator. J Occup Health Psychol 1998;3(4):306-21.

23. Siegrist J, Starke D, Chandola T, Godin I, Marmot M, Niedhammer I, et al. The measurement of Effort-Reward
Imbalance at work: European comparisons. Soc Sci Med 2004;58(8):1483-99.

24. Murphy RL, Harrell JJ. Stress measurement and management in organizations: Development and current status. In: Riley A, Zaccaro S, editors. Occupational Stress and Organizational Effectiveness. New York: Prager Press; 2004.

25. Rijk A de, Le Blanc PM, Schaufeli WB, de Jonge J. Active coping and need for control as moderator of the job demandcontrol model: Effect on burnout. J Occup Organ Psychol 1998;71:1-18.

26. Barbini E, Cevenini G, Scolletta S, Biagioli B, Giomarelli P, Barbini P. A Comparative Analysis of Predictive Models of Morbidity in Intensive Care Unit after Cardiac Surgery Part I: Model Planning. BMC Med Informat Dec Making 2007;7(35) [cited 2007 Nov 22]. Available from URL: http://www.biomedcentral.com/1472-6947/7/35.

27. Van der Klink JJ, Blonk RW, Schene AH, van Dijk FJ. The benefits of interventions for work-related stress. Am J Public Health 2001;91:270-6.

28. DiCiccio TJ, Efron B. Bootstrap confidence intervals. Stat Sci 1996;11(3):189-228.

29. Hacker W. Objective work environment: analysis and evaluation of objective work characteristics. In: Levi L, Petters JL, editors. A Healthier Work Environment: Basic Concept and Methods of Measurement. Stockholm: Hogberga, Lidingo; 1991.

30. Avallone F, Bonaretti M. Organizational well-being. Rome: Rubbettino Editore, Soveria Mannelli; 2003 [in Italian].

31. Pelizzoni B. Administrations in search of organizational wellbeing. Rome: Edizioni Scientifiche Italiane; 2005 [in Italian]. 32. Linstone HA, Turoff M. The Delphi Method: Techniques and Applications. Reading, Massachusets: Adison-Wesley; 1975.

33. Afifi AA, Clark V. Computer-aided multivariate analysis. 3rd ed. London: Chapman and Hall; 1999.

34. Velicer WF, Jackson DN. Component analysis versus common factor analysis: Some issues in selecting an appropriate procedure. Multivariate Behav Res 1990;25(1):1-28.

35. Krzanowski WJ. Principles of Multivariate Analysis: A User's Perspective. Oxford: Clarendon Press; 1988. 
36. Cronbach LJ, Shavelson RJ. My Current Thoughts on Coefficient Alpha and Successor Procedures. Educ Psychol Meas 2004;64(3):391-418.

37. Xu W, Zhao Y, Guo L, Guo Y, Gao W. Job stress and coronary heart disease: A case-control study using a Chinese population. J Occup Health 2009;1(2):107-13.

38. Barbini P, Cevenini G. Design of scoring models for trustworthy risk prediction in critical patients. In: Śmigórski K, editor. Health Management - Different Approaches and Solutions. Rijeka, Croatia: InTech Web Org; 2011:337-60.

39. Fan X. Item Response Theory and Classical Test Theory: An empirical comparison of their item/person statistic. Educ Psychol Meas 1998;58(3):357-81.

40. Singh J. Tackling measurement problems with Item Response Theory: Principles, characteristics, and assessment, with an illustrative example. J Business Res 2004;57:184-208.
41. Fischer GH. Some neglected problems in IRT. Psychometrika 1995;60(4):459-87.

42. Srivastava AK, Krishna A. A test of inverted "U"-hypothesis of stress/performance relationship in the industrial context. Psychol Stud 1991;36:34-8.

43. Koob GF. Arousal, stress, and inverted U-shaped curves: Implications for cognitive function. In: Lister RG, Weingartne HJ, editors. Perspectives on cognitive neuroscience. London: Oxford University Press; 1991. p. 300-13.

44. European Commission. Eurostat, GDP 2007 [cited 2011 Dec 15]. Available from URL: http://epp.eurostat.ec.europa. eu/portal/page/portal/statistics.

45. Italian National Institute of Statistics (ISTAT). National economic account 2010 [cited 2011 Dec 15]. Available from URL: http://en.istat.it/dati/dataset/20110808_00. 
Appendix 1. English translation of the occupational stress detector questionnaire: its original version is in Italian language

\begin{tabular}{|c|c|c|c|}
\hline & Item & Dimension & Axis \\
\hline 1 & I plan and organize the work by myself (e.g. I decide what to do, when and how) & 1 & $\mathrm{R}$ \\
\hline 2 & I have a clear view of the role assigned to me & 1 & $\mathrm{D}$ \\
\hline 3 & I know how the structure is organized and roles inside the company & 1 & $\mathrm{R}$ \\
\hline 4 & Company involves me on scheduled operational changes & 1 & $\mathrm{D}$ \\
\hline 5 & I work in challenging situations in which I can make changes & 1 & $\mathrm{R}$ \\
\hline 6 & My tasks are various and interesting & 1 & $\mathrm{R}$ \\
\hline$\underline{7}$ & I usually work overtime & 2 & $\mathrm{D}$ \\
\hline 8 & Breaks at work are clearly defined & 2 & $\mathrm{D}$ \\
\hline 9 & Working environment is clean and healthy & 2 & $\mathrm{D}$ \\
\hline 10 & Workplace safety rules are strictly followed and applied & 2 & $\mathrm{D}$ \\
\hline$\underline{11}$ & I work in a noisy place & 2 & $\mathrm{D}$ \\
\hline 12 & I was properly trained on all aspects of safety in the workplace & 2 & $\mathrm{R}$ \\
\hline 13 & I consider valuable the internal organization of my workplace & 2 & $\mathrm{D}$ \\
\hline 14 & Allocation in the workload is fair & 2 & $\mathrm{D}$ \\
\hline 15 & Company provides me proper resources and tools to accomplish my tasks & 2 & $\mathrm{D}$ \\
\hline 16 & I can easily complete my daily assignments & 2 & $\mathrm{R}$ \\
\hline 17 & Internal growth is based on credit, commitment and achievements & 3 & $\mathrm{D}$ \\
\hline 18 & I recognize values and mission pursued by the company & 3 & $\mathrm{D}$ \\
\hline 19 & Company sets benefits to the ones who produce and undertake more & 3 & $\mathrm{R}$ \\
\hline 20 & Performance evaluation criteria are clear and defined & 3 & $\mathrm{R}$ \\
\hline 21 & When my work is checked/evaluated, I am informed of the results & 3 & $\mathrm{R}$ \\
\hline 22 & My salary is adequate to the work I do & 3 & $\mathrm{R}$ \\
\hline 23 & There are good chances I can get a promotion & 3 & $\mathrm{R}$ \\
\hline 24 & I consider valuable the strategies and choices adopted by the company & 3 & $\mathrm{D}$ \\
\hline 25 & I have a good understanding and knowledge of the mission and corporate's values & 3 & $\mathrm{R}$ \\
\hline 26 & There are clear guidelines to organize the job properly & 3 & $\mathrm{D}$ \\
\hline 27 & The company creates occasions to communicate for all staff & 3 & $\mathrm{~S}$ \\
\hline 28 & Women have the same career opportunities as men & 3 & $\mathrm{R}$ \\
\hline 29 & Return from maternity leave is facilitated in various ways & 3 & $\mathrm{~S}$ \\
\hline 30 & My colleagues treat me with courtesy and respect & 4 & $\mathrm{~S}$ \\
\hline 31 & With my colleagues I can express myself, talking to them directly and clearly & 4 & $\mathrm{~S}$ \\
\hline 32 & Sometimes there are some misunderstandings between colleagues & 4 & $\mathrm{~S}$ \\
\hline 33 & I know I can trust my colleagues & 4 & $\mathrm{~S}$ \\
\hline$\underline{34}$ & It happens that our superiors give us conflicting information about the progress of work & 4 & $\mathrm{D}$ \\
\hline 35 & With my superiors I can express myself, talking to them directly and clearly & 4 & $\mathrm{~S}$ \\
\hline 36 & Superiors help the staff to increase the professional skills & 4 & $\mathrm{~S}$ \\
\hline
\end{tabular}


Appendix 1. English translation of the occupational stress detector questionnaire: its original version is in Italian language - cont.

\begin{tabular}{llcc}
\hline \multicolumn{1}{c}{ Item } & Dimension & Axis \\
\hline 37 & Superiors evaluate the work of the staff in a clear way, explaining the ratings given & 4 & $\mathrm{~S}$ \\
38 & In our working group we feel members of a team & 4 & $\mathrm{~S}$ \\
39 & At work I am free to express my political views & 4 & $\mathrm{~S}$ \\
$\underline{40}$ & Employees' opinion on labor aspects is constantly ignored & 4 & $\mathrm{~S}$ \\
41 & There's the possibility to benefit of flextime & 5 & $\mathrm{D}$ \\
$\mathbf{4 2}$ & I can get to work by public transport & 5 & $\mathrm{~S}$ \\
43 & I can satisfactory schedule my personal activities relative to my working duties & 5 & $\mathrm{R}$ \\
44 & Working hours of my family members are compatible with mine & 5 & $\mathrm{R}$ \\
$\underline{45}$ & My working ambitions are in conflict with my family life & 5 & $\mathrm{~S}$ \\
46 & My family endorses my work & 5 & $\mathrm{~S}$ \\
$\mathbf{4 7}$ & Services in the area (kindergartens, schools, etc.) are suitable to my needs & 5 & $\mathrm{~S}$ \\
48 & I carry out multiple tasks simultaneously and I'm already thinking about what I do next & 6 & $\mathrm{D}$ \\
49 & I feel that my commitment to the work is useful for the entire company & 6 & $\mathrm{R}$ \\
50 & I work with constancy & 6 & $\mathrm{R}$ \\
51 & I get assigned tasks/activities relevant to my role & 6 & $\mathrm{R}$ \\
52 & I feel fit and full of energy & 6 & $\mathrm{R}$ \\
53 & When I work I try to do better than others & 6 & $\mathrm{R}$ \\
54 & I feel considerably mentally preoccupied with my work & 6 & $\mathrm{D}$ \\
$\mathbf{5 5}$ & I feel integrated into the community where I live & 6 & $\mathrm{~S}$ \\
$\mathbf{5 6}$ & I judge excellent the quality of my life & 6 & $\mathrm{~S}$ \\
\hline
\end{tabular}

Dimensions: 1 - role; 2 - structure and climate; 3 - growth and sensibility; 4 - interpersonal relationships; 5 - work/life balance; 6 - fulfillment. D - demand; R - responsiveness/control; $\mathrm{S}$ - support.

The serial numbers of new items introduced by the Delphi method and items discarded from Cronbach's $\alpha$ analysis are shown in bold and underlined, respectively.

This work is available in Open Access model and licensed under a Creative Commons Attribution-NonCommercial 3.0 Poland License - http://creativecommons.org/ licenses/by-nc/3.0/pl/deed.en. 